\title{
COMPUTED TOMOGRAPHY OF Macrostructure AND Physical PROPERTY VARIABILITY OF SEAFLOOR SEDIMENTS
}

\author{
By Thomas H. Orsi
}

$\mathrm{M}$ ODELS DESIGNED to simulate physical or mechanical phenomena associated with the seafloor often require a knowledge of, or at least an ability to estimate, the physical property structure of the upper portion of the sediment column. High-frequency sound propagation in the uppermost decimeters of the seafloor, for example, is controlled primarily by the spatial density structure of the sediments and the geometry and geotechnical characteristics of volume inhomogeneities, such as shells, rocks, and gas bubbles. Macrostructures (sedimentary features at spatial scales a few centimeters or less) become extremely important at acoustic frequencies approaching $100 \mathrm{kHz}$ and must be considered for realistic scattering models. Biological and hydrodynamic processes are believed to be largely responsible for creating macrostructures, yet the nature and magnitude of variations in sediment physical properties induced by these mechanisms are not well known. A major obstacle to understanding these interactions better is the inability of most traditional analytical techniques to resolve these structures or provide the type of information necessary to develop models in sufficient quantitative detail. Working under Dr. Aubrey L. Anderson on the Naval Research Laboratory-sponsored Coastal Benthic Boundary Layer Special Research Project (CBBL SRP; Richardson, 1994), I addressed these problems in my dissertation by examining spatial relationships between sediment macrostructure and variations in sediment physical properties (Orsi, 1994). Defining the significance of environmental processes in the development of these relationships was particularly important.

T.H. Orsi, Department of Oceanography, Texas A\&M University, College Station, TX 77843-3146. USA (present address is Neptune Sciences, Inc., 150 Cleveland Ave., Slidell, LA 70458).
The first phase of my research focused on the lack of a suitable quantitative technique with the resolution necessary to analyze the internal macrostructure of intact marine sediment cores. I employed X-ray computed tomography (CT or CAT scanning) after modifying a medical $\mathrm{CT}$ scanner for use with marine sediment cores (Orsi et al., 1994). A calibration scheme was then devised to quantify the scanner's submillimeter spatial resolution and strong linear response to sediment bulk density. With an estimated average density resolution much less than $0.01 \mathrm{~g} \mathrm{~cm}^{-3}$, the extreme sensitivity of the CT scanner to sediment bulk density is invaluable because this engineering parameter is often needed for numerical seafloor simulations. A single regression relationship for converting CT numbers to sediment bulk density could not be developed, but the cores were calibrated individually with excellent results (average $r=0.90$ ). It is unclear whether a single equation can be established given the existence of many uncontrollable environmental and machine variables, such as variations in sample sedimentology, problems arising from small sample statistics, deficiencies in techniques for sample preparation, and nonlinear effects caused by the polychromatic X-ray beam. The additional time needed for individual calibrations versus using a single equation is insignificant and far overshadowed by the advantages of CT, i.e., the capacity to automate scan sequences, the submillimeter horizontal sampling scale, and the benefit of two- and three-dimensional visualization of sediment macrostructures.

In the second phase of the study, I conducted a comparative CT scan examination of sediment cores from Eckernförde Bay (western Baltic Sea) and the Louisiana continental shelf and slope (northern Gulf of Mexico). Distinct environmental and geotechnical differences were found between regions. Sources of macrostructural variability in-
Biological and

hydrodynamic

processes are

believed to be

largely responsible

for creating

macrostructures, . . . 
(a)

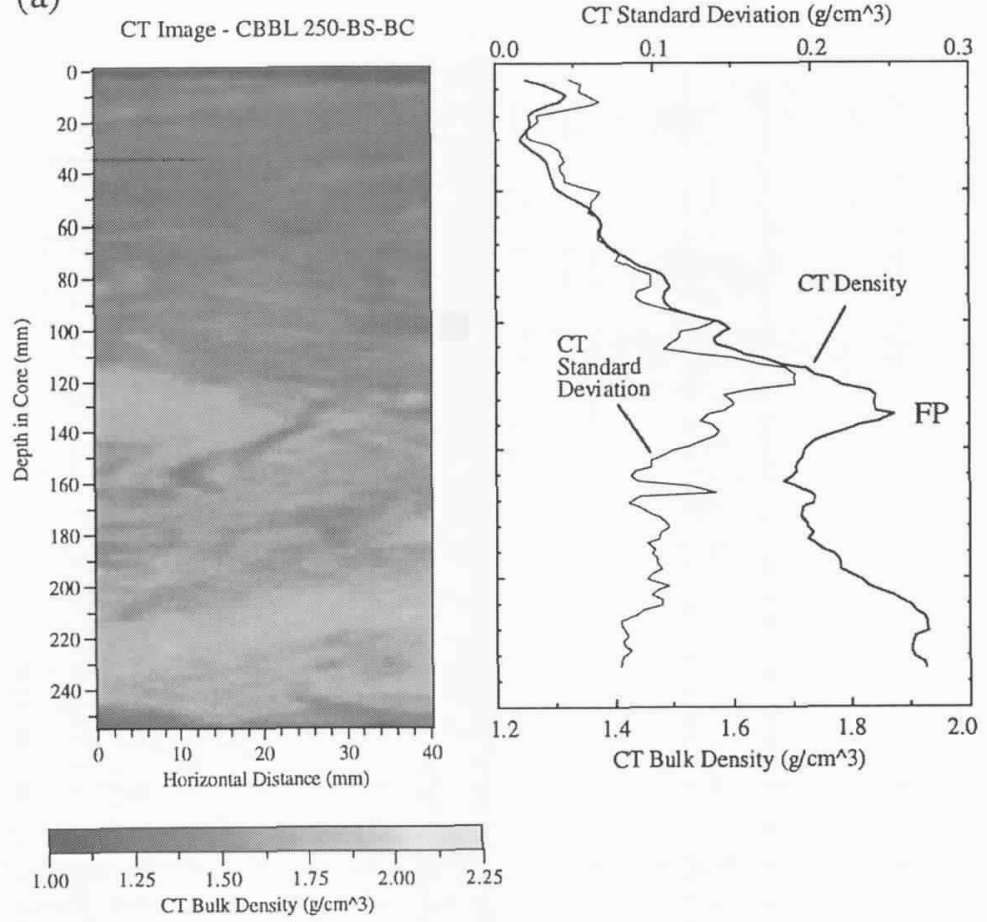

Fig. 1: Reconstructed vertical CT sections (left) and sediment depth profiles of CT bulk density and its standard deviation (right) of cores from Eckernförde Bay, western Baltic Sea: (a) CBBL 250-BS-BC, southwestern flank of Mittelgrund; and (b) CBBL 227-BS-BC, central bay. L, lamina; B, burrowed zone; FP, feeding pocket.

Reworking by hurri-

cane wave surges

resulted in significant

variability ... cluded feeding pockets (advective or "conveyor belt" benthic mixing), shells and shell debris, worm tubes, and laminae, (listed in approximate order of decreasing importance). Interestingly, for the Baltic site, sediment variability induced by burrowing was insignificant overall, although the activity produced structures readily discernable by $\mathrm{CT}$. The greatest CT variability occurred in the heavily bioturbated (advective) muddy sands and silts at the base of Mittelgrund, a ridge composed of glacial rock debris at the mouth of the bay (Fig. 1a). The lowest CT variability was associated with the muds of the central bay where smaller scale horizontal burrowing and thin silty storm laminae produce minor density variations (Fig. 1b). In the northern Gulf of Mexico, CT variability was highest within deposits on the Louisiana continental shelf, although radiographs and geotechnical properties of the cores suggested a completely "homogenized" seafloor. Reworking by hurricane wave surges resulted in significant variability due to the randomization of shells and creation of localized macrostructures. Further offshore on the continental slope, CT variability decreased: laminae were not uncommon in these sediments, but only slight increases in CT variability were associated with the structures. Presumably, the lack of significant density contrast is a result of their fine- grained nature. Furthermore, as in Eckernförde Bay, burrowing resulted in only small macrostructural variability.

For both the western Baltic Sea and the northern Gulf of Mexico, grain size is the major parameter characterizing sediment macrostructure, with the largest CT variability occurring in silty sand and the lowest in clay. The sorting capacity of an environmental process is critical in assessing its role in generating sediment heterogeneity. For example, consider a sediment interval classified as a silty sand according to traditional grain size analysis. The spatial distribution of silt particles within the sand mass, whether patchy or uniform, is more important in evaluating sediment heterogeneity and variations in physical properties than the integrated grain size value. Thus, in addition to determining grain size, the type of process dictates the geometry of the resulting heterogeneity or structure. In general, hydrodynamic processes generate horizontal to subhorizontal structures, whereas conveyor or advective mixing creates more or less unpredictable three dimensional structures. This generalization is not always true because the reverse can also be observed, for example, in the generation of laminae via biogenic grading. Nonetheless, the geometry and expected magnitude of physical property 
(b)

CT Image - CBBL 227-BS-BC
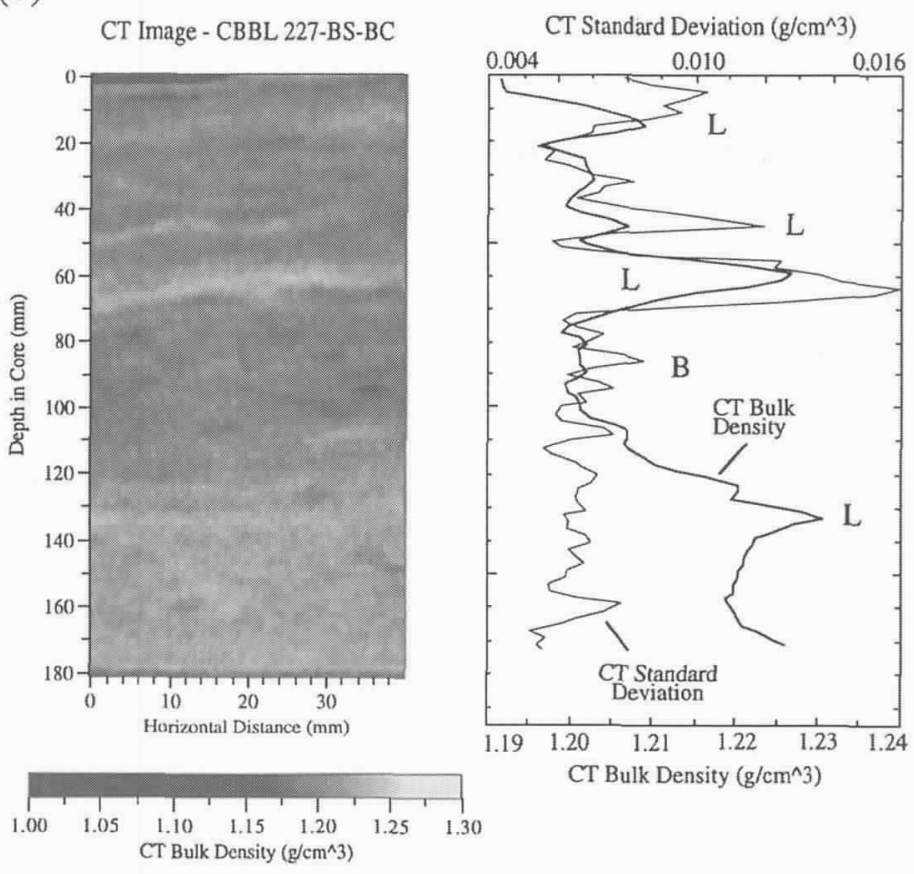

Fig. 1: Continued.

variability associated with specific macrostructures are important considerations for many numerical simulations of seafloor sediments.

Based on the preceeding results, I related downcore characteristics of sediment macrostructure and physical property variability using a tiered conceptual model for the final phase of my research. Following the Berger-Ekdale formulation for seafloor structure of carbonates (Berger, 1982; Ekdale et al., 1984), the model consists of the following layers listed in order of increasing subbottom depth: 1) mixed layer - low bulk densities with moderately high variability due to intense small-scale (meiofaunal) burrowing; 2) transitional layer - moderately high bulk densities and high property variability caused by largescale mixing by head-down-feeding organisms and; 3) historical layer - rapid increase in density with a simultaneous decrease in variability as open burrows and other voids close. In fact, mechanical compaction (consolidation) increased substantially at extremely shallow subseafloor depths (10 $\mathrm{cm}$ or less), illustrating its importance in the development of macrostructure of the upper decimeters of the seafloor, in addition to hydrodynamic and biological processes.

I am now applying the CT scan technique to sediment cores collected from CBBL SRP study sites off Panama City and Key West, FL, to evaluate similar relationships for terrigenous sands and carbonate muds. CT is exceptionally well-suited for characterizing sands and fossiliferous sediments, two sediment types that historically have been difficult to sample, and thus characterize quantitatively, because of their lack of cohesion and the presence of shells.

\section{Acknowledgements}

This study was funded by research grants to Dr. Aubrey Anderson from the Office of Naval Research (ONR) and the Naval Research Laboratory (NRL). I thank Dr. Joseph Kravitz (ONR) and Dr. Michael Richardson (NRL) for their encouragement and support of this research. I extend my sincere appreciation to Dr. Anderson and Dr. William Bryant who co-chaired my advisory committee; I thank other committee members, Dr. Niall Slowey, Dr. Wayne Dunlap, Dr. Richard Bennett, and Dr. Carl Edwards for commenting on various stages of my research. My thanks also to Dr. Charles Nittrouer, Dr. Glenn Lopez, Nancy Craig, Dr. Kathleen Fischer, Dr. Armand Silva, and Dr. Horst Brandes who permitted me to subsample their box cores. An Office of Naval Research-National Defense Science and Engineering Grant (ONR-NDSEG) fellowship provided much-needed financial support. 


\section{References}

Berger, W.H., 1982: The benthic interface of deep-sea carbonates: a three-tiered sequence controlled by depth of deposition. In: The Dynamic Environment of the Ocean Floor, K.A. Fanning and F.T. Manheim, eds. Lexington Books, Lexington, MA, 95-114.

Ekdale, A.A., L.N. Muller and T. Novak, 1984: Quantitative ichnology of modern pelagic deposits in the abyssal Atlantic. Palaeogeogr. Palaeoclimatol. Palaeoecol., 45, 189-223.

Orsi, T.H., 1994: Computed tomography of macrostructure and physical property variability of seafloor sediments. Ph.D. thesis. Texas A\&M University. College Station. TX. $184 \mathrm{pp}$.

. C.M. Edwards and A.L. Anderson, 1994: X-ray computed tomography: a non-destructive method for quantitative analysis of sediment cores. J. Sed. Res. A64, 690-693.

Richardson, M.D., 1994: Investigating the coastal benthic boundary layer. EOS, Trans. Amer. Geophys. Union, 75. 201. 205-206. 